\title{
Salt Tolerance of Desorption Electrospray Ionization (DESI)
}

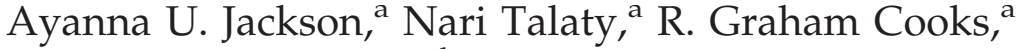 \\ and Gary J. Van Berkel ${ }^{b}$ \\ ${ }^{a}$ Department of Chemistry, Purdue University and Bindley Bioscience Center, Discovery Park at Purdue \\ University, West Lafayette, Indiana, USA \\ ${ }^{\mathrm{b}}$ Organic and Biological Mass Spectrometry Group, Oak Ridge National Laboratory, Oak Ridge, Tennessee, \\ USA
}

The salt tolerance of desorption electrospray ionization (DESI) was systematically investigated by examining three different drug mixtures in the presence of $0,0.2,2,5,10$, and $20 \% \mathrm{NaCl}: \mathrm{KCl}$ (1:1) from different surfaces. At physiological salt concentrations, the individual drugs in each mixture were observed in each experiment. Even at salt concentrations significantly above physiological levels, particular surfaces were effective in providing spectra that allowed the ready identification of the compounds of interest in low nanogram amounts. Salt adducts, which are observed even in the absence of added salt, could be eliminated by adding $0.1 \% 7$ $\mathrm{M}$ ammonium acetate to the standard methanol:water (1:1) spray solvent. Comparison of the salt tolerance of DESI with that of electrospray ionization (ESI) demonstrated better signal/ noise characteristics for DESI. The already high salt tolerance of DESI can be optimized further by appropriate choices of surface and spray solution. (J Am Soc Mass Spectrom 2007, 18, 2218-2225) (C) 2007 American Society for Mass Spectrometry

$\mathrm{D}$ esorption electrospray ionization (DESI) is an ionization technique in which the sample of interest is examined in the ordinary ambient environment [1,2]. The method involves electrospraying a solvent to generate charged microdroplets that impact a condensed-phase sample and extracts analyte molecules in situ. Secondary droplets containing analyte ions are sucked by the vacuum into the atmospheric sampling interface of a mass spectrometer. In various cases, complex biological mixtures have been analyzed successfully with little or no sample preparation [3-9]. In these and other previous studies, the preliminary indications were that DESI has a high salt tolerance. These studies did not explore the limits of this tolerance as a function of salt concentration, nor were the effects of the nature of the substrate or the possibility that additives in the spray solution might prevent the formation of salt adducts studied. Each of these enquiries is undertaken here.

The underlying reasons for ion suppression effects has been a subject of interest in several electrospray ionization (ESI) mass spectrometry studies [10-14]. A mechanistic investigation into this phenomenon concluded that it is more likely to occur in the liquid than in the gas phase, and that it can be ascribed to the presence of high concentrations of non-volatile compounds, such as salts and endogenous metabolites [10,

Address reprint requests to Dr. R. Graham Cooks, Purdue University, Department of Chemistry, 1393 HC Brown Laboratory, West Lafayette, IN 47907. E-mail: cooks@purdue.edu
12-14]. Non-volatile materials like salts alter the efficiency of droplet formation, which in turn negatively affects the number of ions reaching the mass spectrometer. In highly concentrated samples $\left(>10^{-5} \mathrm{M}\right)$, there is competition among analyte ions during droplet formation for outer surface space and this is believed to contribute to ion suppression [11]. Ion suppression is also thought to occur due to the masking of analytes by matrix ions of greater polarity or even by high mass compounds masking lower mass analytes [10, 12].

The successes of DESI in a large variety of applications [4, 6, 15-19] are partly due to the availability of various surfaces from which the sample can be analyzed and, even more important, due to the ability to optimize the spray solvent for the analyte(s) of interest. Addition of a selective reagent to the solvent spray can be used to enhance the analyte signal by an appropriate chemical reaction; an experiment that is termed reactive DESI [20-22]. By the inverse argument, possibly appropriate reagents added to the spray solution might reduce signals due to unwanted ions; such an action would increase the salt tolerance of DESI. The addition of ammonium acetate to the buffer in electrospray ionization is known to counteract signal suppression effects of metal salts in ESI [14] so this reagent is explored with DESI in this study.

This investigation into salt tolerance has been carried out using three different drug mixtures at physiological concentrations that are typical of drug abusers [23]. With favorable surfaces, samples containing as much as $20 \%$ weight by volume salt (approximately ten times 
Table 1. Summary of compounds analyzed

\begin{tabular}{|c|c|c|c|c|}
\hline & $\begin{array}{c}\text { Molecular } \\
\text { weight }\end{array}$ & $\begin{array}{c}\text { Physiological } \\
\text { concentration [25] }\end{array}$ & $\begin{array}{l}\text { LOD in } 2 \% \text { salt } \\
\text { by DESI }\end{array}$ & $\begin{array}{c}\text { Amount analyzed } \\
\text { by DESI }\end{array}$ \\
\hline \multicolumn{5}{|c|}{ MISCELLANEOUS MIXTURE } \\
\hline Cocaine & 303 & $\sim 150 \mathrm{ng} / \mathrm{mL}$ & $\begin{array}{c}\sim 0.017 \mu \mathrm{M} \\
3 \mu \mathrm{L} \text { spot } \sim 7.5 \mathrm{pg} \\
(\sim 2.5 \mathrm{ng} / \mathrm{mL})\end{array}$ & $\begin{array}{c}\sim 12.0 \mu \mathrm{M} \\
3 \mu \mathrm{L} \text { spot } \sim 10.8 \mathrm{ng}\end{array}$ \\
\hline Diacetylmorphine & 369 & $\sim 300 \mathrm{ng} / \mathrm{mL}$ & $\begin{array}{c}0.271 \mu \mathrm{M} \\
3 \mu \mathrm{L} \text { spot } \sim 0.15 \mathrm{ng} \\
(\sim 50 \mathrm{ng} / \mathrm{mL})\end{array}$ & $\begin{array}{c}\sim 9.9 \mu \mathrm{M} \\
3 \mu \mathrm{L} \text { spot } \sim 10.8 \mathrm{ng}\end{array}$ \\
\hline Methamphetamine & 149 & $\sim 500 \mathrm{ng} / \mathrm{mL}$ & $\begin{array}{c}0.067 \mu \mathrm{M} \\
3 \mu \mathrm{L} \text { spot } \sim 0.03 \mathrm{ng} \\
(\sim 10 \mathrm{ng} / \mathrm{mL})\end{array}$ & $\begin{array}{c}\sim 24.5 \mu \mathrm{M} \\
3 \mu \mathrm{L} \text { spot } \sim 10.8 \mathrm{ng}\end{array}$ \\
\hline \multicolumn{5}{|c|}{ BENZODIAZEPINE MIXTURE } \\
\hline Nordiazepan & 270 & $\sim 300 \mathrm{ng} / \mathrm{mL}$ & $\begin{array}{c}0.037 \mu \mathrm{M} \\
3 \mu \mathrm{L} \text { spot } \sim 0.03 \mathrm{ng} \\
(\sim 10 \mathrm{ng} / \mathrm{mL})\end{array}$ & $\begin{array}{c}\sim 18.0 \mu \mathrm{M} \\
3 \mu \mathrm{L} \text { spot } \sim 14.5 \mathrm{ng}\end{array}$ \\
\hline Diazepam & 285 & $\sim 20 \mathrm{ng} / \mathrm{mL}$ & $\begin{array}{c}0.025 \mu \mathrm{M} \\
3 \mu \mathrm{L} \mathrm{spot} \sim 0.021 \mathrm{ng} \\
(\sim 7 \mathrm{ng} / \mathrm{mL})\end{array}$ & $\begin{array}{c}\sim 17.1 \mu \mathrm{M} \\
3 \mu \mathrm{L} \text { spot } \sim 14.5 \mathrm{ng}\end{array}$ \\
\hline Carbamazepine & 237 & $\sim 300 \mathrm{ng} / \mathrm{mL}$ & $\begin{array}{c}1.45 \mu \mathrm{M} \\
3 \mu \mathrm{L} \text { spot } \sim 1.2 \mathrm{ng} \\
(\sim 400 \mathrm{ng} / \mathrm{mL})\end{array}$ & $\begin{array}{c}\sim 20.6 \mu \mathrm{M} \\
3 \mu \mathrm{L} \text { spot } \sim 14.5 \mathrm{ng}\end{array}$ \\
\hline \multicolumn{5}{|c|}{ BARBITURATE MIXTURE } \\
\hline Hexobarbital & 236 & $\sim 300 \mathrm{ng} / \mathrm{mL}$ & $\begin{array}{c}0.424 \mu \mathrm{M} \\
3 \mu \mathrm{L} \text { spot } \sim 0.3 \mathrm{ng} \\
(\sim 100 \mathrm{ng} / \mathrm{mL})\end{array}$ & $\begin{array}{c}20.9 \mu \mathrm{M} \\
3 \mu \mathrm{L} \text { spot } \sim 14.5 \mathrm{ng}\end{array}$ \\
\hline Phenobarbital & 232 & $\sim 300 \mathrm{ng} / \mathrm{mL}$ & $\begin{array}{c}1.29 \mu \mathrm{M} \\
3 \mu \mathrm{L} \text { spot } \sim 0.9 \mathrm{ng} \\
(\sim 300 \mathrm{ng} / \mathrm{mL})\end{array}$ & $\begin{array}{c}\sim 19.3 \mu \mathrm{M} \\
3 \mu \mathrm{L} \text { spot } \sim 13.4 \mathrm{ng}\end{array}$ \\
\hline Aprobarbital & 210 & $\sim 300 \mathrm{ng} / \mathrm{mL}$ & $\begin{array}{c}0.476 \mu \mathrm{M} \\
3 \mu \mathrm{L} \text { spot } \sim 0.3 \mathrm{ng} \\
(\sim 100 \mathrm{ng} / \mathrm{mL})\end{array}$ & $\begin{array}{c}\sim 23.1 \mu \mathrm{M} \\
3 \mu \mathrm{L} \text { spot } \sim 13.4 \mathrm{ng}\end{array}$ \\
\hline \multicolumn{5}{|c|}{ OLIGONUCLEOTIDE } \\
\hline $\mathrm{C} 6: 3^{\prime}-(\mathrm{CCCCCC})-5^{\prime \prime}$ & 1673.1 & $\mathrm{~N} / \mathrm{A}$ & $\mathrm{N} / \mathrm{A}$ & $\begin{array}{c}1.20 \mathrm{mM} \\
3 \mu \mathrm{L} \text { spot } \sim 5.3 \mu \mathrm{g}\end{array}$ \\
\hline
\end{tabular}

physiological salt concentrations ( $\sim 0.5-2 \%$ salt $)[14,24])$ were successfully analyzed for the individual drugs in low nanogram amounts.

\section{Experimental}

\section{Drug Standards and Sample Preparation}

Solvents and reagents were obtained from Mallinckrodt Baker, Inc. (Phillipsburg, NJ). Drug standards (Quikchek $^{\mathrm{TM}}$ ) were obtained from Alltech Applied Science Lab (State College, PA), and labeled drug standards were obtained from Cerilliant (Roundrock, TX, USA). The hexameric oligonucleotide, cytosine (C)6:5'-CCCCCC-3', was synthesized by Integrated DNA Technologies (Coralville, IA). All water used came from a Millipore Milli Q unit at $18.2 \mathrm{M} \Omega \cdot \mathrm{cm}$.

The three drug mixtures examined included a "miscellaneous" mixture (methamphetamine, cocaine, and diacetylmorphine), a benzodiazepine mixture (diazepam, nordiazepam, and carbamazepine), and a barbiturate mixture (aprobarbital, hexobarbital, and phenobarbital) as summarized in Table 1. Each mixture consisted of the three drug standards each at a concentration of $50 \mu \mathrm{g} / \mathrm{mL}$, in a 1:1:1 volumetric ratio (Table 1). Separate salt solutions ( $\mathrm{NaCl}: \mathrm{KCl}(1: 1)$ weight by volume) of $0(0 \mathrm{mM}), 0.2$ (28 $\mathrm{mM}), 2$ (154 mM), $5(614 \mathrm{mM}), 10\left(1.02 \times 10^{3} \mathrm{mM}\right)$, and $20 \%\left(1.54 \times 10^{3} \mathrm{mM}\right)$ were added to each drug mixture for a total of eighteen different samples. Samples were stored in a $5^{\circ} \mathrm{C}$ refrigerator when not in use.

\section{Mass Spectrometry}

DESI experiments were performed using a Thermo Finnigan LTQ (San Jose, CA, USA) fitted with a Prosolia, Inc. Omni Spray ${ }^{\mathrm{TM}}$ Ion Source. Using typical DESI conditions $[1,2], 3 \mu \mathrm{L}$ sample solutions containing varying concentrations of salt were analyzed from a variety of surfaces. Samples spotted onto porous surfaces tend to spread over a larger area $\left(\sim 12 \mathrm{~mm}^{2}\right)$ than those on smooth surfaces $\left(\sim 3 \mathrm{~mm}^{2}\right)$. Optimal positioning of the sample stage and DESI spray source was achieved for each surface by maximizing the DESI ion signal. Samples were analyzed 

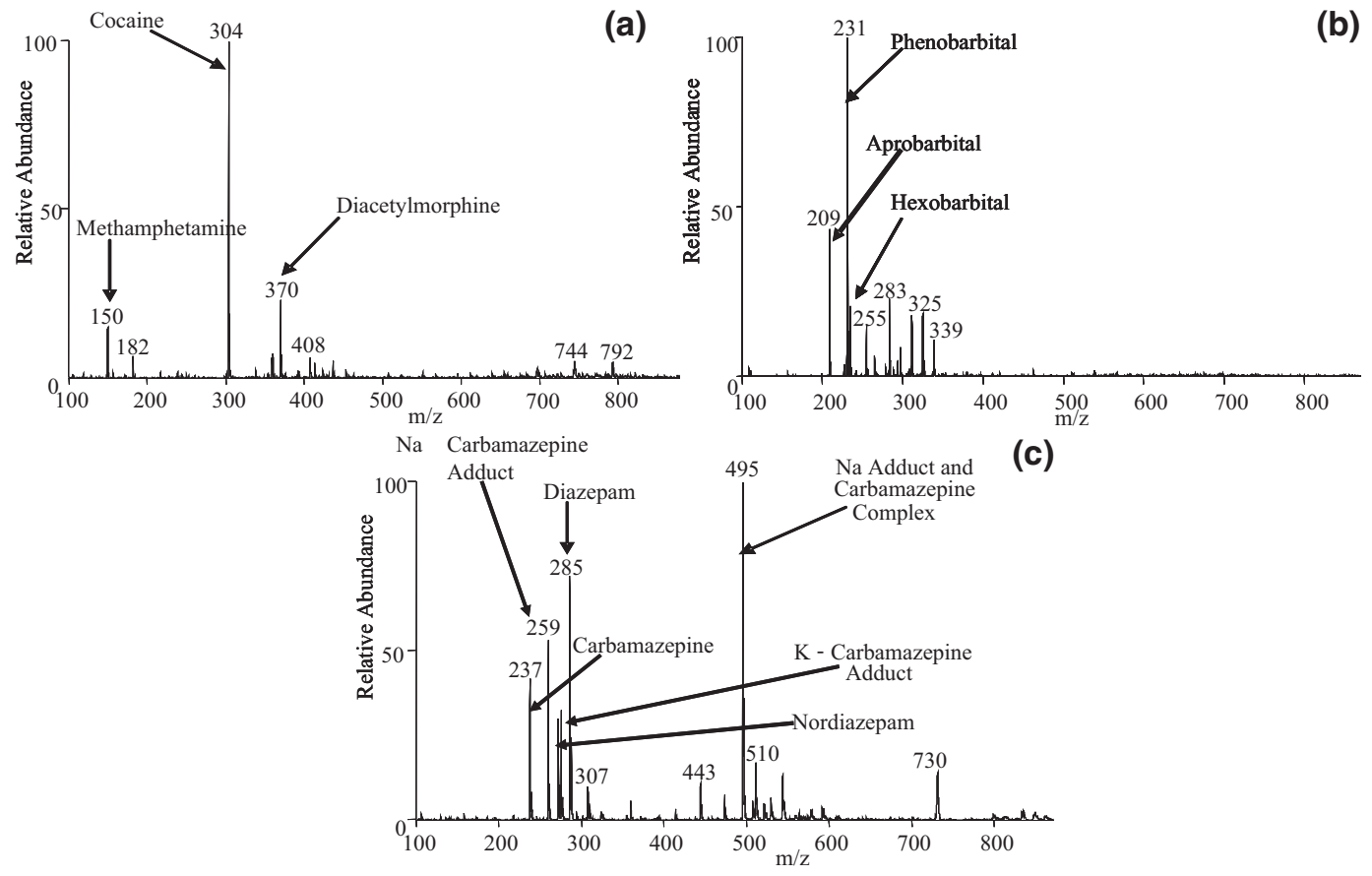

Figure 1. Analysis of drug mixtures: each mixture was analyzed by DESI using a ThermoFisher LTQ and methanol:water (1:1) solvent spray on a Teflon (PTFE) surface at upper physiological salt concentrations [ $2 \%$ weight by volume $\mathrm{NaCl}: \mathrm{KCl}(1: 1)]$. (a) miscellaneous mixture (7.7 ng of each drug); (b) barbiturate mixture (10 ng of each drug); (c) benzodiazepine mixture (10 ng of each drug)

by manually rastering each spotted sample until it was completely depleted from the surface with averaging of the data to give the resulting mass spectrum. A standard solvent spray of methanol:water (1:1) was used. The miscellaneous mixture and benzodiazepines were analyzed in the positive-ion mode, whereas the barbiturates and the oligonucleotide were analyzed in the negative-ion mode. Additional DESI experiments were carried out to analyze the benzodiazepine mixture, the constituents of which readily formed cationic adducts with alkali ions. When indicated, the solvent spray was optimized by adding $0.1 \% 7 \mathrm{M}$ ammonium acetate, which reacted readily with the salt ions, inhibiting the formation of salt adducts.

Collision-induced dissociation (CID) experiments were performed to confirm the presence of each individual drug within the sample mixture. These experiments were done using an isolation window of 1.5 mass/charge units (full width) and $25-40 \%$ (manufacturer's units) collision energy. CID was done on the standard mixtures, in the presence and absence of salt, as well as on available labeled drug standards.

ESI experiments were conducted for the hexameric oligonucleotide in the negative ion mode. The experiments were conducted using a Thermo Finnigan LTQ (San Jose, CA) fitted with a Finnigan ${ }^{\mathrm{TM}}$ Ion Max API source. The conditions for the analysis included a sheath gas flow of 50 (manufacturer's units), source voltage of $5 \mathrm{kV}$, capillary temperature of $275^{\circ} \mathrm{C}$, and solvent flow rate of $13 \mu \mathrm{L} / \mathrm{min}$.

\section{Treatment of Surfaces Used}

The surfaces used in this study included brown Kraft envelope paper, Whatman \#1 filter paper (Maidstone, UK), Teflon (polytetrafluoroethylene, PTFE), Fisher finest premium fully frosted microscope slides (Pittsburgh, PA), Merck KGaA UTLC plates (Darmstadt, Germany), Esco clipped-corner sandblasted frosted microscope slides (Erie Scientific Portsmouth, NH), and Gold Seal beveled plain (uncoated) glass microscope slides (Portsmouth, NH). The fully frosted microscope slides, UTLC plates, and sandblasted microscope slides were soaked in water, acetonitrile, and methanol, respectively, for about 5-10 min to clean them before use.

\section{Results and Discussion}

\section{Mixture Analysis}

Three mixtures containing varying amounts of salts were analyzed from seven different surfaces by DESIMS. Each of the mixtures was analyzed from Teflon (PTFE) at levels above and below physiological salt concentrations (Figure 1). No significant suppression effect was observed in the physiological range of salt concentrations except for the benzodiazepine mixture. In this case, the suppression effect was overcome by optimizing the solvent spray, as detailed later. Compared to the literature, the average amount of salt in the samples spotted is about ten times higher than the lowest physiological concentrations [25]. The drug sam- 
ples analyzed contain drugs of abuse in concentrations that correspond to those encountered at physiological concentrations in the urine samples of typical abusers, as analyzed by GC-MS [23].

To confirm that the identities of the molecular ions of each of the analytes in the mixtures were correctly assigned, product ion MS/MS spectra were recorded using collision-induced dissociation (CID) and compared to the spectra recorded using standard solutions in the absence of salt. The assignments were further confirmed in some cases using deuterated standards of the drugs. The product ions of the drugs studied agree with data reported [26-30]. Multiple stage mass spectrometric analysis up to the $\mathrm{MS}^{5}$ level was performed in the case of select compounds examined from the salt matrix (Figure S1, which can be fournd in the electronic version of this article).

\section{Optimization of Surface and the Limits of Salt Tolerance}

The drug mixtures (Table 1) were examined from seven different surfaces, including paper, PTFE, and a variety of coated glasses. The degree of ion suppression varied with the surface. In the case of all three drug mixtures, PTFE proved to be the surface from which the analytes suffered the least signal suppression, as illustrated in Figure 2. This figure is a plot of the average logarithm mass spectra signal intensity for the most abundant component in each mixture as a function of the salt concentration. The dominant molecular ions are protonated cocaine $(\mathrm{m} / \mathrm{z} 304)$, sodiated carbamazepine $(\mathrm{m} / \mathrm{z}$ 495), and deprotonated phenobarbital $(\mathrm{m} / \mathrm{z} 231)$ for the miscellaneous drug, benzodiazepine, and barbiturate mixtures, respectively. The figure represents a compact summary of the salt tolerance for each drug mixture analyzed from each surface.

The shaded region in each of the plots in Figure 2 corresponds to the physiological salt concentration range, $0.08-0.15 \mathrm{M}$. Below this region, each mixture could be analyzed with minimal ion suppression from most of the surfaces used in the analysis. A quantitative measure of ion suppression is the ratio of the signal intensity for the monitored ions (protonated cocaine, sodiated carbamazepine, and deprotonated phenobarbital) to the total signal intensity. At concentrations above those in the shaded region in Figure 2, ion suppression began to increase for the majority of the surfaces. The paper and coated glass surfaces produced complete ion suppression of the analyte ions at the highest salt concentrations in all mixtures except the benzodiazepine mixture, where the fully frosted glass surface showed analyte ions with about $30 \%$ of the intensity recorded in the absence of added salt. PTFE proved to be the optimal surface for these experiments yielding the highest average signal intensity and negligible ion suppression except at the higher salt concentrations. Suppression by 21, 1, and 27\% occurred for the (a) Miscellaneous Mixture

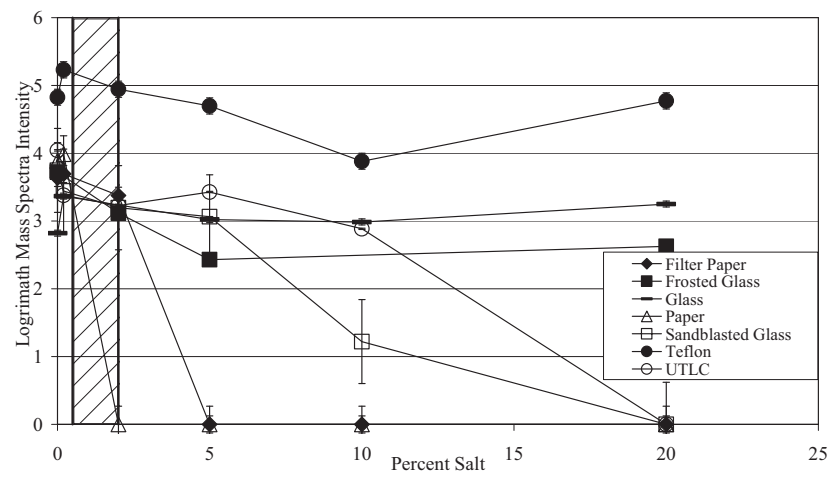

(b)

Benzodiazepine Mixture

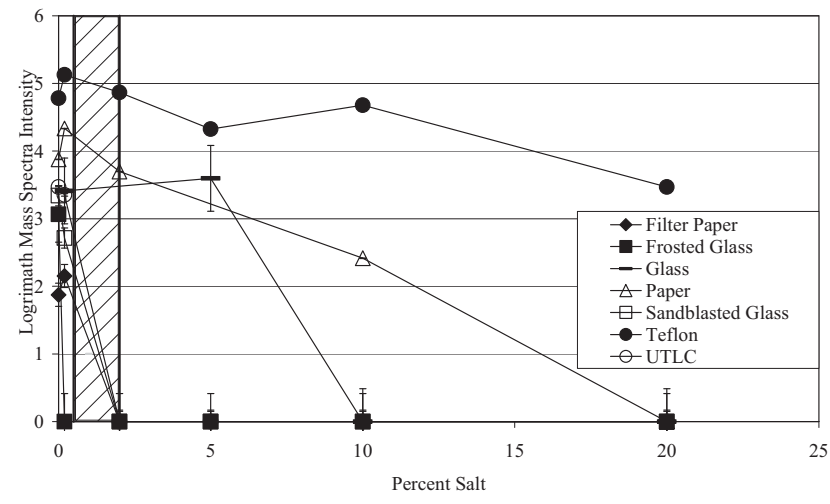

(c) Barbiturate Mixture

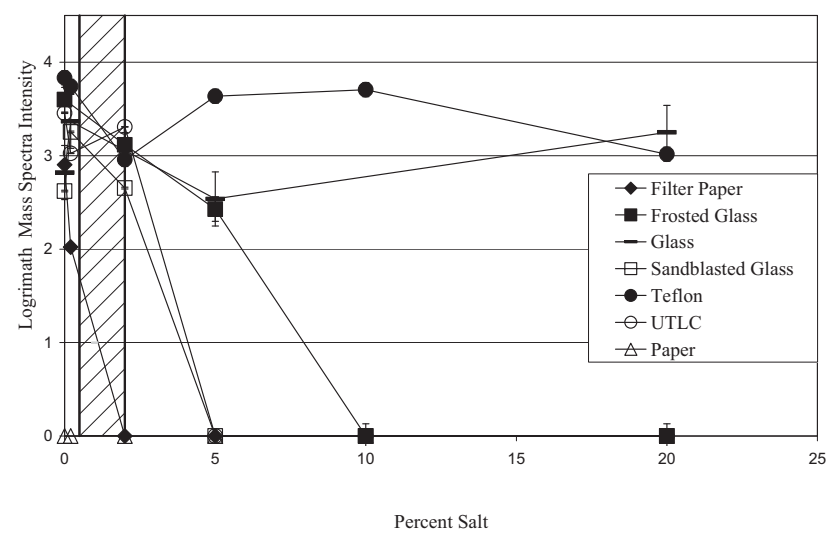

Figure 2. Surface analysis of salt tolerance: seven different surfaces were analyzed to evaluate the salt tolerance of DESI. Samples were spotted three times and analyzed using LTQ. A methanol:water (1:1) solvent spray was used. The full spectrum was averaged for each spot. The signal of the prominent peak in each mixture profile was averaged and plotted against the percentage of salt present. For the miscellaneous, barbiturates, and benzodiazepine mixture the prominent peak monitored was protonated cocaine $(\mathrm{m} / \mathrm{z} 304)$, hexobarbital $(m / z 231)$, and sodium-carbamazepine adduct $(m / z 495)$, respectively. The shaded region in each plot is an indication of the physiological salt concentration range. The error bars correspond to the average variation in signal intensity for the given surface: (a) miscellaneous mixture; (b) benzodiazepine mixture; (c) barbiturate mixture.

major observed analyte in the barbiturate, miscellaneous, and benzodiazepine mixtures, respectively, at the highest salt concentration ( $20 \%$ weight by volume). 

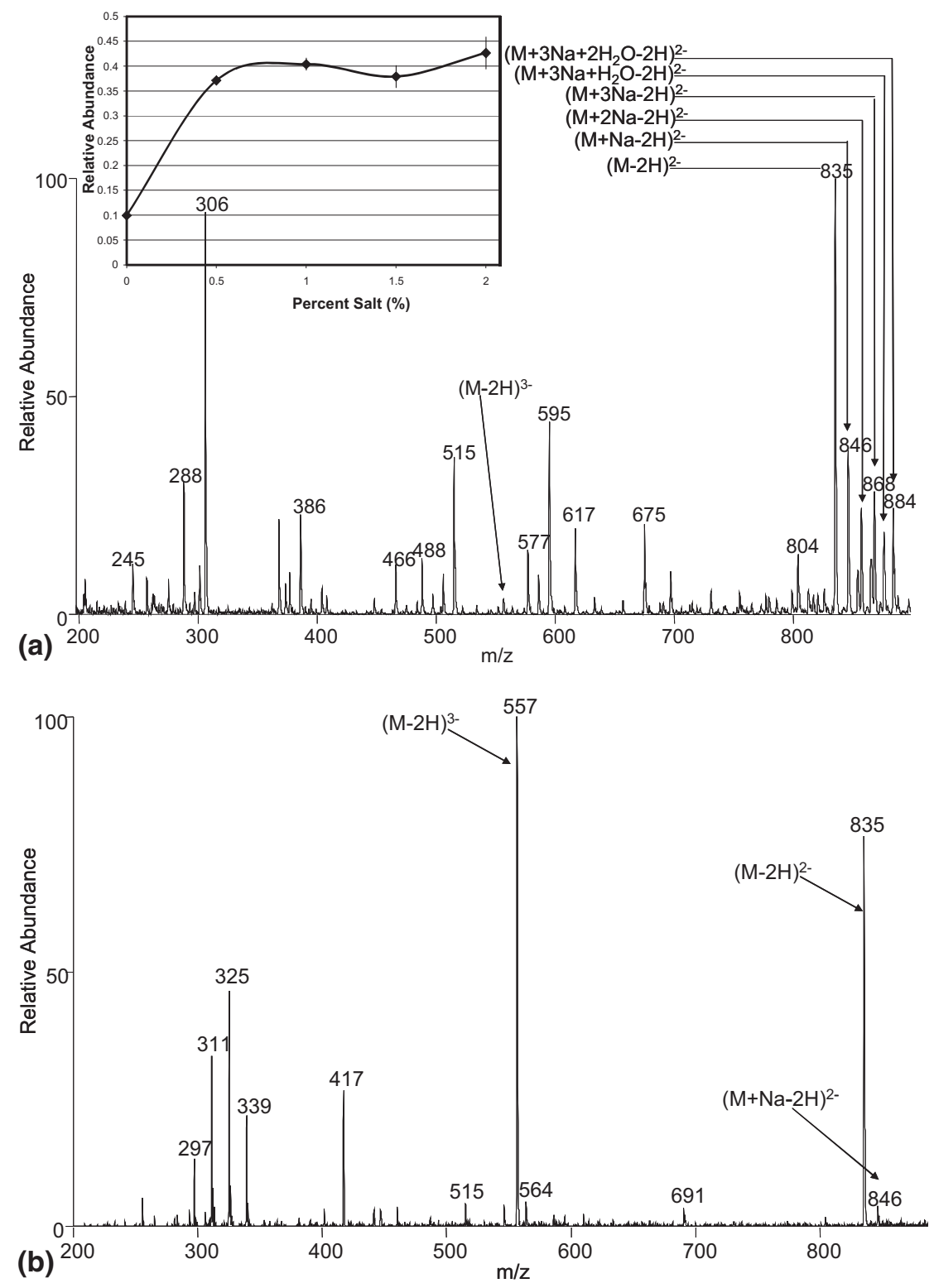

Figure 3. Comparison of ESI and DESI spectra of a hexameric oligonucleotide: a hexameric oligonucleotide ( $3 \mu \mathrm{g}$ ) was analyzed by ESI and DESI at upper physiological salt concentrations, $2 \%$ salt weight by volume using an LTQ. (a) Spectrum of ESI analysis. The inset plot illustrates the onset of adduct formation with respect to salt concentration. (b) Spectrum of DESI analysis using a methanol:water (1:1) solvent spray from PTFE.

The non-coated glass surface yielded ion intensities resulting in $15 \%$ ion suppression for the barbiturate and benzodiazepine mixtures, but $100 \%$ ion suppression (analytes not observed in full mass spectra) for the analytes of interest was observed for the miscellaneous mixture at $20 \%$ salt weight by volume.

The remaining surfaces produced complete ion suppression for the drugs when analyzed in the presence of $5 \%$ salt weight by volume. Paper typically provides long-lasting stable signals for samples analyzed by DESI and has proven to be the optimal surface in several metabolomic studies $[6,31]$. The previous analyses used diluted serum and urine samples. This study suggests that analysis of raw serum and urine is possi- ble, but is best done from a PTFE or a non-coated glass surface for positive and negative ions not from a paper substrate. The data further illustrate, that analysis from paper at the lower physiological salt concentrations is possible with minimal ion suppression, which agrees well with the results of previous studies $[6,31]$.

\section{Oligonucleotide Salt Tolerance Analysis}

To extend the range of analytes investigated for salt tolerance, we evaluated the behavior of an oligonucleotide, a class of compounds typically difficult to ionize by ESI, without extensive sample preparation [32].

Using PTFE, which proved to be the least salt- 


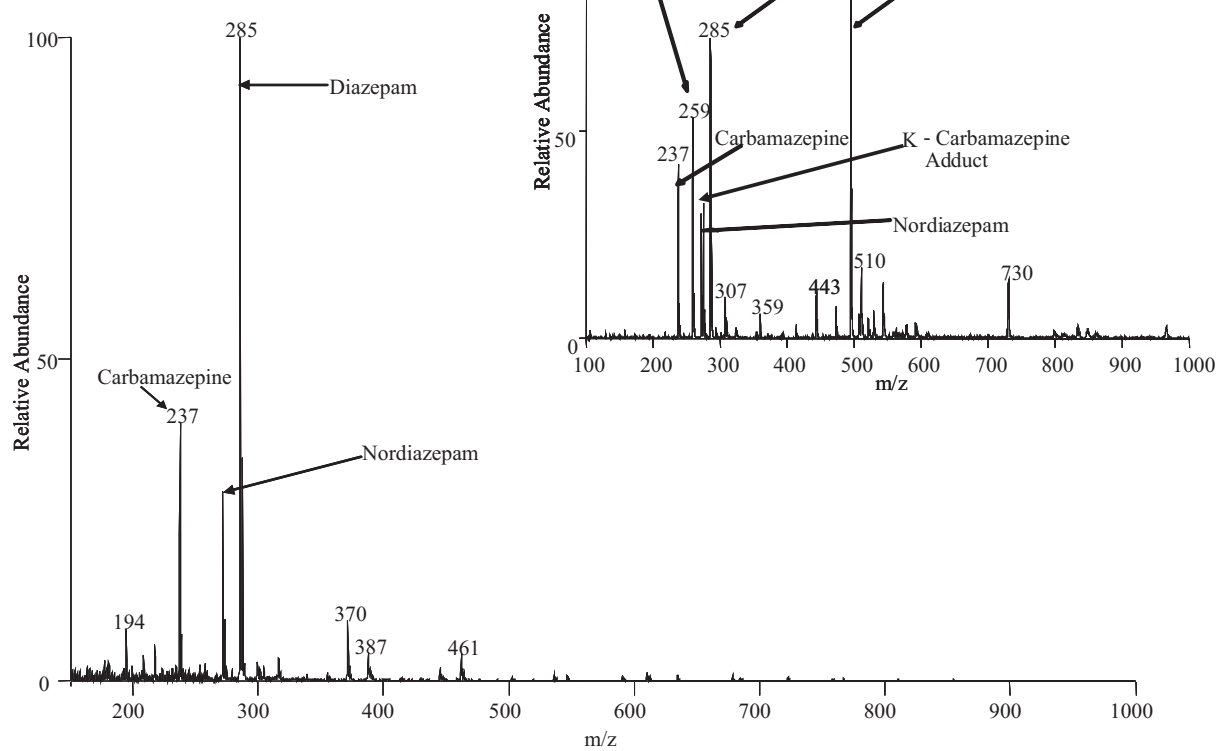

Figure 4. DESI analysis of benzodiazepine mixture: analysis of benzodiazepine mixture from PTFE illustrating the presence of sodium $(\mathrm{m} / \mathrm{z} 259)$, potassium $(\mathrm{m} / \mathrm{z} 275)$, and sodium-carbamazepine $(\mathrm{m} / \mathrm{z}$ 495 ) adducts in $2 \%$ salt weight by volume (inset). Upon the addition of $0.1 \% 7 \mathrm{M} \mathrm{NH}_{4} \mathrm{CH}_{3} \mathrm{COO}$ to the solvent spray, the adducts were eliminated. The experiment was done using a standard methanol: water (1:1) solvent spray.

sensitive surface in the drug study, the salt tolerance of a hexameric oligonucleotide, cytosine $(\mathrm{C}) 6: 5^{\prime}$-CCCCCC$3^{\prime}$, was evaluated. At high physiological salt concentrations, the sample was easily ionized in the negative ion mode with minimal formation of adducts, even when ionized in varying salt solutions. Several charge states of the oligonucleotide were identified. For example, $\mathrm{C}_{6}{ }^{3-}$ and $\mathrm{C}_{6}{ }^{2-}$ charge states corresponding to $\mathrm{m} / \mathrm{z}$ values 557 and 835, respectively, were observed. Even at the highest concentration of salt, $20 \%$ salt weight by volume, there was only a $39 \%$ ion suppression of signal when the signal of $\mathrm{C}_{6}{ }^{3-}$ was monitored.

To evaluate the results from DESI, the same hexameric oligonucleotide $(1.2 \mathrm{mM})$ was also analyzed by ESI at the upper end of the range of physiological salt concentrations, $2 \%$ weight by volume. A comparison of the two ionization techniques in the examination of the hexameric oligonucleotide is made (Figure 3). It is evident from the ESI mass spectrum, Figure $3 a$, that several salt and water adducts form $(\mathrm{m} / \mathrm{z}$ 846, 857, $868,876,884)$ and suppress the ion intensity of some of the various charge states of the oligonucleotide $\left(\mathrm{C}_{6}{ }^{3-}\right.$ and $\left.\mathrm{C}_{6}{ }^{2-}\right)$. Adduct formation increases rapidly with salt concentration also. By comparison, analysis by DESI (Figure 3b) shows minimal adduct formation $(\mathrm{m} / \mathrm{z} 884$ is less than $10 \%$ of the normalized ion intensity). In this particular case, the salt tolerance of DESI is superior to ESI because ESI typically requires sample preparation and extraction methods to isolate the analyte of interest and reduce adduct formation.

\section{Influence of Solvent Spray}

In the case of the benzodiazepine mixture (diazepam, nordiazepam, and carbamazepine), carbamazepine tended to be ionized by cationization rather than protonation. Carbamazepine formed abundant sodium $(\mathrm{m} / \mathrm{z}$ 259), potassium $(\mathrm{m} / \mathrm{z} 275)$ and sodium-carbamazepine $(\mathrm{m} / \mathrm{z}$ 495) adducts even without the deliberate addition of salt. These and other adducts masked the ions of interest $(\mathrm{m} / \mathrm{z}$ 237,271 , and 285) and cluttered the spectrum. To enhance the signal of the ions of interest and prevent the cationization of carbamazepine, the solvent spray was optimized by adding $0.1 \% 7 \mathrm{M}$ ammonium acetate to $100 \mathrm{~mL}$ MeOH: $\mathrm{H}_{2} \mathrm{O}$ (1:1) solvent, which results in a $7 \mathrm{mM}$ ammonium acetate $\mathrm{MeOH}: \mathrm{H}_{2} \mathrm{O}$ spray solvent. The addition of this reagent greatly suppressed or eliminated (at physiological concentrations of salt) the formation of these adducts as illustrated in Figure 4.

\section{Limit of Detection and Ionization Efficiency}

To evaluate the influence of the salt ions on the limit of detection (LOD) (signal to noise ratio $\geq 3$ ), cocaine was evaluated in the absence and presence of physiological concentrations of salt (Figure S2). In the absence of salt, the LOD of cocaine was about $1.55 \mathrm{pg}$. Little ion suppression was observed in the presence of $2 \%$ salt weight by volume and the LOD of cocaine increased modestly to about $7.5 \mathrm{pg}$. The LODs of each drug in the presence of $2 \%$ salt is summarized in Table 1 . The observed detection limits are well below the lowest 

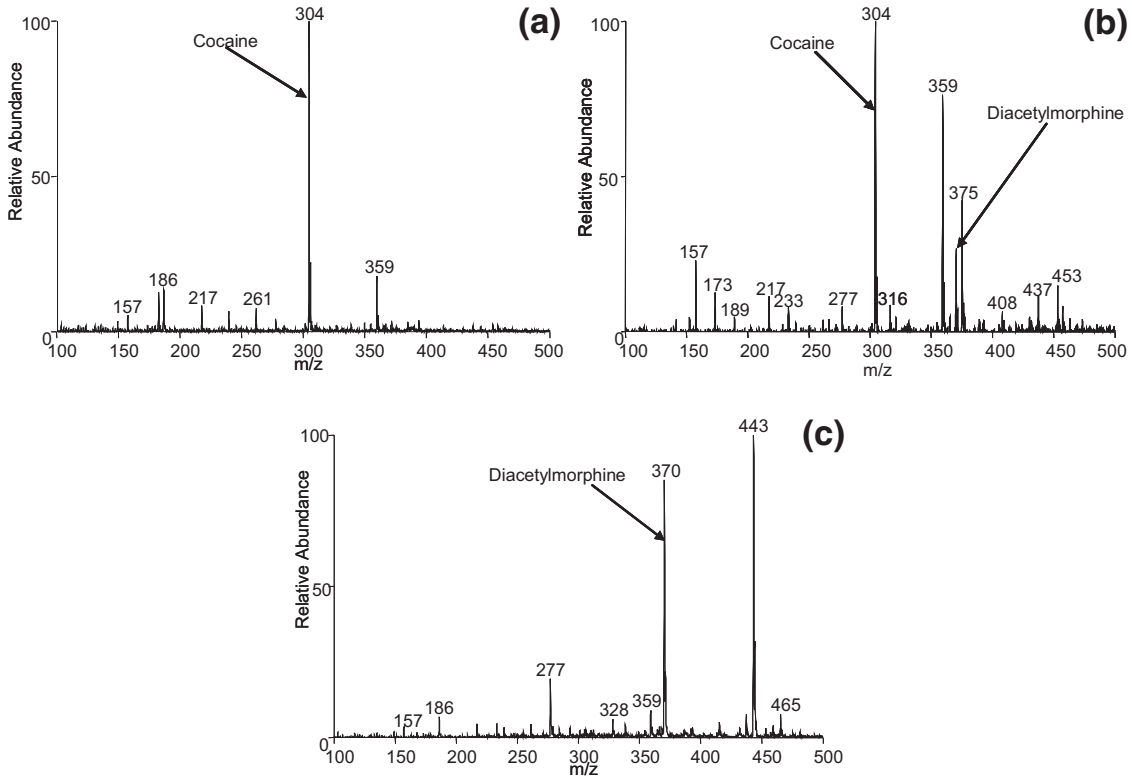

Figure 5. Ionization efficiency analysis of cocaine and diacetylmorphine in the presence of $2 \%$ salt weight by volume. The ionization efficiency of cocaine was evaluated in the presence of increasing diacetylmorphine concentrations. The lowest detectable amount of the cocaine was within the picogram range with increasing concentrations of diacetylmorphine. (a) cocaine $\left(10^{-6} \mathrm{M}\right)$ in the presence of diacetylmorphine $\left(10^{-15} \mathrm{M}\right) ;(\mathbf{b})$ cocaine $\left(10^{-7} \mathrm{M}\right)$ in the presence of diacetylmorphine $\left(10^{-7} \mathrm{M}\right) ;(\mathbf{c})$ cocaine $\left(10^{-15} \mathrm{M}\right)$ in the presence of diacetylmorphine $\left(10^{-6} \mathrm{M}\right)$.

reported physiological concentrations [25]. These results not only illustrate the high salt tolerance of DESI but also the sensitivity demonstrated by this ionization technique.

The ionization efficiency and salt tolerance of DESI was investigated using a series of cocaine and diacetylmorphine (heroin) mixtures (Figure 5) in which cocaine and diacetylmorphine concentrations varied inversely. The absolute amount of each analyte ranged from $10^{-9}$ to $10^{-15} \mathrm{~g}$ in $2 \%$ salt weight by volume for a total of seven samples. In the presence of increasing amounts of diacetylmorphine, cocaine is readily detected in the full mass spectrum at levels as low as about 7.5 pg. Diacetylmorphine was not readily detected at such low amounts in the presence of increasing cocaine but was detected at about $0.15 \mathrm{ng}$. The greater proton affinity of cocaine is illustrated in Figure $5 b$ where equal concentrations of cocaine and diacetylmorphine were evaluated at $10^{-7}$ $M$ yet the cocaine peak is dominant. Therefore, cocaine is both easily ionizable by DESI and is less susceptible to salt effects when compared to diacetylmorphine.

\section{Conclusion}

This study of the salt tolerance of DESI, as investigated through the analysis of drug mixtures in the presence of various salt concentrations and using different surfaces, establishes that DESI is more tolerant of the presence of salts than is ESI. The salt tolerance of DESI is also highly surface dependent. Optimization of the solvent spray permits the analysis of samples in extremely low concentrations and in the presence of very complex sample matrices. Such applications can be further developed and optimized for other classes of compounds and specific matrices such as serum, blood, and urine.

\section{Acknowledgments}

This work is supported by the Frederick N. Andrews Fellowship (to AUJ), the W. Brooks Fortune Fellowship (to NT), and the NIH Roadmap Initiative on Metabolomics Technology, NIH/NIDDK 3 R21 DK-070290-01. Gary J. Van Berkel was supported at ORNL by the Division of Chemical Sciences, Geosciences and Biosciences, Office of Basic Energy Sciences, United States Department of Energy. ORNL is managed and operated by UT-Battelle, LLC, for the United States Department of Energy under Contract DE-AC05$00 \mathrm{OR} 22725$.

\section{References}

1. Takats, Z.; Wiseman, J. M.; Cooks, R. G. Ambient Mass Spectrometry Using Desorption Electrospray Ionization (DESI): Instrumentation, Mechanisms and Applications in Forensics, Chemistry, and Biology. J. Mass Spectrom. 2005, 40, 1261-1275.

2. Cooks, R. G.; Ouyang, Z.; Takats, Z.; Wiseman, J. M. Ambient Mass Spectrometry. Science 2006, 31, 1566-1570.

3. Kauppila, T. J.; Wiseman, J. M.; Ketola, R. A.; Kotiaho, T.; Cooks, R. G.; Kostiainen, R. Desorption Electrospray Ionization Mass Spectrometry for the Analysis of Pharmaceuticals and Metabolites. Rapid Commun. Mass Spectrom. 2006, 20, 387-392.

4. Leuthold, L. A.; Mandscheff, J. F.; Fathi, M.; Giroud, C.; Augsburger, M.; Varesio, E.; Hopfgartner, G. Desorption Electrospray Ionization Mass Spectrometry: Direct Toxicological Screening and Analysis of Illicit Ecstasy Tablets. Rapid Commun. Mass Spectrom. 2006, 20, 103-110.

5. McEwen, C. N.; McKay, R. G.; Larsen, B. S. Analysis of Solids, Liquids, and Biological Tissues Using Solids Probe Introduction at Atmospheric Pressure on Commercial LC/MS Instruments. Anal. Chem. 2005, 77, 7826-7831.

6. Pan, Z.; Gu, H.; Talaty, N.; Chen, H. W.; Hainline, B. E.; Cooks, R. G.; Raftery, D. Principal Component Analysis of Urine Metabolites Detected by NMR and DESI-MS in Patients with Inborn Errors of Metabolism. Anal. Bioanal. Chem. 2006, 387, 539-549. 
7. Rodriguez-Cruz, S. E. Rapid Analysis of Controlled Substances Using Desorption Electrospray Ionization Mass Spectrometry. Rapid Commun. Mass Spectrom. 2006, 20, 53-60.

8. Talaty, N.; Takats, Z.; Cooks, R. G. Rapid In Situ Detection of Alkaloids in Plant Tissue under Ambient Conditions Using Desorption Electrospray Ionization. Analyst 2005, 130, 1624-1633.

9. Weston, D. J.; Bateman, R.; Wilson, I. D.; Wood, T. R.; Creaser, C. S. Direct Analysis of Pharmaceutical Drug Formulations Using Ion Mobility Spectrometry/Quadrupole-Time-of-Flight Mass Spectrometry Combined with Desorption Electrospray Ionization. Anal. Chem. 2005, $77,7572-7580$

10. Annesley, T. M. Ion Suppression in Mass Spectrometry. Clin. Chem. 2003, 49, 1041-1044.

11. Jessome, L. L.; Volmer, D. A. Ion Suppression: A Major Concern in Mass Spectrometry. LCGC North America 2006, Suppl., 83-89.

12. King, R.; Bonfiglio, R.; Fernandez-Metzler, C.; Miller-Stein, C.; Olah, T. Mechanistic Investigation of Ionization Suppression in Electrospray Ionization. J. Am. Soc. Mass Spectrom. 2000, 11, 942-950.

13. Iribarne, J. V.; Thomson, B. A. On the Evaporation of Small Ions from Charged Droplets. J. Chem. Phys. 1976, 64, 2287-2294.

14. Iavarone, A. T.; Udekwu, O. A.; Williams, E. R. Buffer Loading for Counteracting Metal Salt-Induced Signal Suppression in Electrospray Ionization. Anal. Chem. 2004, 76, 3944-3950.

15. Chen, H. W.; Talaty, N. N.; Takats, Z.; Cooks, R. G. Desorption Electrospray Ionization Mass Spectrometry for High-Throughput Analysis of Pharmaceutical Samples in the Ambient Environment. Anal. Chem. 2005, 77, 6915-6927.

16. Cotte-Rodriguez, I.; Takats, Z.; Talaty, N.; Chen, H. W.; Cooks, R. G. Desorption Electrospray Ionization of Explosives on Surfaces: Sensitivity and Selectivity Enhancement by Reactive Desorption Electrospray Ionization. Anal. Chem. 2005, 77, 6755-6764.

17. D'Agostino, P. A.; Hancock, J. R.; Chenier, C. L.; Lepage, C. R. J. Liquid Chromatography Electrospray Tandem Mass Spectrometric and Desorption Electrospray Ionization Tandem Mass Spectrometric Analysis of Chemical Warfare Agents in Office Media Typically Collected During a Forensic Investigation. J. Chromatogr. A 2006, 1110, 86-94.

18. Gu, H.; Chen, H.; Pan, Z.; Jackson, A. U.; Talaty, N.; Xi, B.; Kissinger, C.; Duda, C.; Mann, D.; Raftery, D.; Cooks, R. G. Monitoring Diet Effects from Biofluids and Their Implications for Metabolomics Studies. Anal. Chem. 2006, 79, 89-97.

19. Williams, J. P.; Scrivens, J. H. Rapid Accurate Mass Desorption Electrospray Ionization Tandem Mass Spectrometry of Pharmaceutical Samples. Rapid Commun. Mass Spectrom. 2005, 19, 3643-3650.

20. Chen, H.; Cotte-Rodriguez, I.; Cooks, R. G. Cis-Diol Functional Group Recognition by Reactive Desorption Electrospray Ionization (DESI). Chem. Commun. 2006, 6, 597-599.

21. Nyadong, L.; Newton, P. N.; Green, M. D.; De Jesus, V.; Fernandez, F. M. Reactive Desorption Electrospray Ionization Mass Spectrometry for High-Throughput Screening of Essential Antimalarials. In Proceedings of the 58th Southeast Regional Meeting of the American Chemical Society, Augusta, GA, 2006.

22. Jackson, A. T.; Williams, J. P.; Scrivens, J. H. Desorption Electrospray Ionization Mass Spectrometry and Tandem Mass Spectrometry of Low-Molecular-Weight Synthetic Polymers. Rapid Commun. Mass Spectrom. 2006, 20, 2717-2727.

23. Kauppila, T. J.; Talaty, N.; Kuuranne, T.; Kotiaho, T.; Kostiainen, R.; Cooks, R. G. Rapid Analysis of Metabolites and Drugs of Abuse from Urine Samples by Desorption Electrospray Ionization-Mass Spectrometry. Analyst 2006, 132, 868-875.

24. Henry, R. J. Clinical Chemistry Principles and Technics; Harper \& Row Publishers: New York, 1964.

25. Cone, E. J. Saliva Testing for Drugs of Abuse. Ann. N. Y. Acad. Sci. 1993, 694, 91-127.

26. Rooka, E. J.; Hillebrand, M. J. X.; Rosing, H.; van Reeb, J. M.; Beijnen, J. H. The Quantitative Analysis of Heroin, Methadone and Their Metabolites and the Simultaneous Detection of Cocaine, Acetylcodeine and Their Metabolites in Human Plasma by High-Performance Liquid Chromatography Coupled with Tandem Mass Spectrometry. J. Chromatogr. B 2005, 824, 213-221.

27. Iwai, M.; Hattori, H.; Arinobu, T.; Ishii, A.; Kumazawa, T.; Noguchi, H.; Noguchi, H.; Suzuki, O.; Seno, H. Simultaneous Determination of Barbiturates in Human Biological Fluids by Direct Immersion SolidPhase Microextraction and Gas Chromatography-Mass Spectrometry. J. Chromatogr. B 2004, 806, 65-73.

28. Hummel, D.; Löffler, D.; Fink, G.; Ternes, T. A. Simultaneous Determination of Psychoactive Drugs and Their Metabolites in Aqueous Matrices by Liquid Chromatography Mass Spectrometry. Environ. Sci. Technol. 2006, 40, 7321-7328.

29. Smyth, W. F.; McClean, S.; Ramachandran, V. N. A Study of the Electrospray Ionization of Pharmacologically Significant 1,4-Benzodiazepines and Their Subsequent Fragmentation Using an Ion-Trap Mass Spectrometer. Rapid Commun. Mass Spectrom. 2000, 14, 2061-2069.

30. Wang, J.; Shen, X.; Fenyk-Melody, J.; Pivnichny, J. V.; Tong, X. Simple and Sensitive Liquid Chromatography/Tandem Mass Spectrometry Method for the Determination of Diazepam and Its Major Metabolites in Rat Cerebrospinal Fluid. Rapid Commun. Mass Spectrom. 2003, 17, 519-525.

31. Chen, H. W.; Pan, Z. Z.; Talaty, N.; Raftery, D.; Cooks, R. G. Combining Desorption Electrospray Ionization Mass Spectrometry and Nuclear Magnetic Resonance for Differential Metabolomics without Sample Preparation. Rapid Commun. Mass Spectrom. 2006, 20, 1577-1584.

32. Guo, X.; Bruist, M. F.; Davis, D. L.; Bentzley, C. M. Secondary Structural Characterization of Oligonucleotide Strands Using Electrospray Ionization Mass Spectrometry. Nucleic Acids Res. 2005, 33, 3659-3666. 